\title{
Thoracic duct cyst presenting as a left supraclavicular mass
}

\author{
K R Chapman ${ }^{1}$ and P C A Ratnatunga ${ }^{2}$
}

(Index words: Lymphoscintigraphy, lymphocystography, cyst fluid composition, histology).

\section{Summary}

Thoracic duct cysts may occur either in the mediastinum or in the neck. The majority of such lesions occurring in the neck consist of chylous fistulae and are secondary to surgery on the neck. Fewer than five cases have been reported in the literature of primary thoracic duct cysts occurring in the neck (1).

\section{Case report}

A 46-year old woman was admitted to our surgical unit in July 1998 with a history of discomfort in the left side of the neck especially when typing and exercising the left arm, and a swelling above the left clavicle of one year's duration. She had undergone subtotal thyroidectomy for a multinodular goitre in 1980 . There were no malignant changes reported in the thyroid tissue. Following this the patient was asymptomatic until admission to our unit.

The mass had a smooth surface. It was fluctuant, non-pulsatile, non-transilluminant and not compressible. No thrill or bruit was apparent.

The patient underwent fine needle aspiration cytology of the mass in April 1998. Cytology of the $50 \mathrm{ml}$ of milky fluid showed numerous lymphocytes and histiocytes with intra- and extracellular fat globules. The cyst was regarded to be of lymphatic origin. An ultrasound scan revealed a large $6 \times 4 \mathrm{~cm}$ clearly defined unilocular cyst in the left supraclavicular fossa. The cyst was aspirated dry but refilled in 7 days. A lymphoscintigraphy with injection of Technitium ${ }^{99}$ subcutaneously in the left iliac region showed tracer uptake in to the lymphatic system, but delayed images ( 3 hours, 4 hours) failed to demonstrate tracer in the thoracic duct area. Lymphocystography done using radio-opaque contrast material (Figure) demonstrated a well-defined left supraclavicular cyst with a smooth outline and a narrowed pedicle like structure. The thoracic duct itself was not visualised. Chest radiographs showed soft tissue swelling with minimum tracheal compression. The mediastinal structures and lung fields were normal.

She underwent surgery for complete excision of the cyst in the July 1988 under a general anaesthetic. A smooth white walled cyst with dilated lymphatic vessels running on its surface was found at surgery. The medial margin and lower part of the cyst was located postero-lateral to the internal jugular vein. The cyst pedicle was seen to be arising from the thoracic duct close to its insertion at the venous angle. However it was unclear whether the pedicle connecting the cyst to the thoracic duct was patent. This tissue connection was ligated. No evidence of neoplastic infiltration or lymph node enlargement was detected. A few inadvertently divided lymphatic vessels were ligated to prevent fistulation. The postoperative period was uneventful.

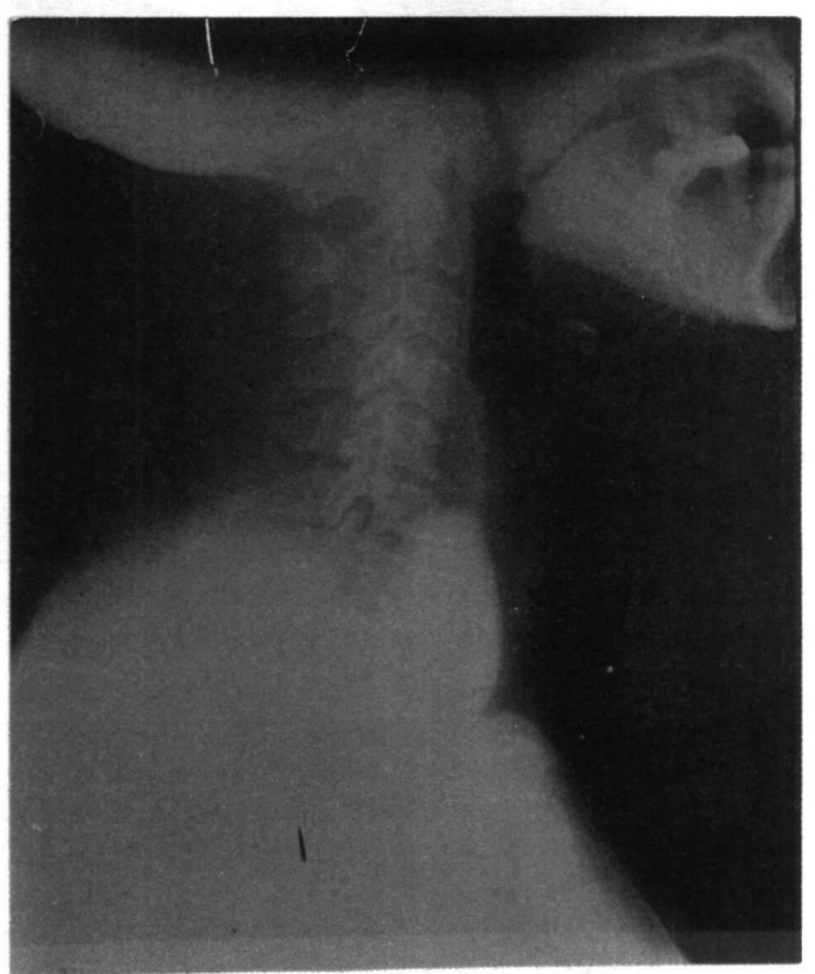

Figure. Lymphocystography of cyst, lateral view.

The unilocular thin walled cyst measured $6 \mathrm{~cm} \times 4.5 \mathrm{~cm}$ showing areas of flattened endothelium. The cyst wall showed a fibro-elastic tissue with focal myxoid change. A lymphatic infiltrate was seen in some areas of the wall. The surrounding fibro-fatty tissue was permeated with lymphatics and collections of smaller dilated lymphatics. The histological appearance was consistent with that of a benign thoracic duct cyst showing lymphangitis and lymphangiectasis of the surrounding lymphatics.

About $60 \mathrm{ml}$ of milky chyle contained in the cyst consisted of triglycerides $(2550 \mathrm{mg} / \mathrm{dl})$, cholesterol $(328 \mathrm{mg} / \mathrm{dl})$, high density lipoproteins $(180 \mathrm{mg} / \mathrm{dl})$.

\section{Comment}

Thoracic duct terminates at the origin of the left brachiocephalic venous trunk via a dilation (ampulla). The 
average width of this ampulla is 4 to $5 \mathrm{~mm}$ and if larger than $7 \mathrm{~mm}$, would be considered abnormal (2). Proximal dilatation or cyst formation suggests outflow obstruction. Such obstructions are usually secondary, and have been reported as being due to subclavian venous thrombosis, metastatic disease, lymphomas and filariasis (2). Large cystic dilations due to such obstructions have been reported (4). As further consequences of such obstruction, retrograde flow via the anatomic inflow afferents in cervical, axillary and bronchomediastinal lymph trunks can cause proximal dilatation and tissue dysfunction as in the lung, and fistulation as seen in a chylothotrax (2).

Primary thoracic duct cyst in the neck is a rare clinical entity. Information regarding the natural history of these cysts and their pathogenesis is limited. A weakness in the wall of the thoracic duct either on a congenital or degenerative basis has been postulated (5). In view of the histological appearance of the cyst in our report, we would also consider an obstructive cause. Lymphography has been helpful in visualising lymph vessels on the surface of these cysts as well as the thoracic duct in close proximity to the cysts $(6,7)$. Plain radiographs of the chest and neck, ultrasonography, computerised axial tomography and magnetic resonance imaging are useful in determining the anatomical boundaries and their cystic nature. The differential diagnosis of these lesions is important as careless tissue handling could lead to complications such as chylothorax or chylous fistulae. The definitive diagnosis rests on the histological demonstration of lymphatic tissue of thoracic duct origin and the intra-operative finding of a structural connection with the thoracic duct. The chyle obtained from these cysts characteristically has a high lipid and triglyceride content (8). Elk and Laine have concluded that pressure within the thoracic duct system modulates the composition of lymph (9). Surgical excision following adequate imaging of thoracic duct cysts arising in the neck is feasible with often satisfactory results if one is mindful of the lymphatic nature and proximity of these cysts to important anatomical structures. Our patient remains well and back at work.

\section{Acknowledgements}

We thank Dr R M P Ratnayake and Prof N V I Ratnatunga for the histopathology, Asiri Diagnostic Services, Kandy, for the biochemical analysis of the lipids, and Dr B Hewavithana and Dr Chandragupta Udugama for help with the imaging.

\section{References}

1. Masuda R, Furuhata $Y$, Kasahara D, Tanaka I, Inoue M, Takemura $T$. Preoperative diagnosis of a thoracic duct cyst arising in the supraclavicular fossa - surgical case report. NipponKyobu-Geka-Gakkai-Zasshi 1992: 40(2): 320-5.

2. Kinmouth J B. The lymphatics. $2^{\text {nd }}$ Edition. London: Edwin Amold, 1982: 54-5.

3. Rusnak I, Foldi M, Szabog. Lymphatics and lymph circulation. Oxford: Pergammon press, 1967: 504.

4. Arvay N, Picard J D. La Lymphoglaphie. Marson, Parris, as quoted by Kinmouth JB. The Lymphatics. London: Edwin Arnold, 1982: 54-5.

5. Wax $M K$, Treloar M E. Thoracic duct cyst: an unusual supraclavicular mass. Head-Neck 1992; 14: 502-5.

6. Morettin L B, Allen T E. Thoracic duct cyst: Diagnosis with needle aspiration. Radiology 1986; 161: 437-8.

7. Maruyama M, Kobayashi S, Kasuga Y, Fugimori M, Yokoyama $\mathrm{S}$, Shingu $\mathrm{K}$, et al. Thoracic duct cyst in the supraclavicular region. Ulster Medical Journal 1997; 66: 140-3.

8. Sakamoto H, Uda H, Sata A, Tanaka S, Kuwabara H, Miyauchi A. Thoracic duct cyst in the neck: a case report. Lymphology 1991; 24: 130-4.

9. Elk J R, Laine G A. Pressure within the thoracic duct modulates lymph composition. Microvascular Research 1990; 39: 315 21. 